\title{
ENTRE PAREDES ESTUDANTIS E INSTITUCIONAIS: O MOVIMENTO ESTUDANTIL, SUAS POSIÇÕES E LUTAS
}

\author{
Orlando Lima Pimentel1
}

\begin{abstract}
Resumo: Pretendemos desenvolver neste texto comentários sobre o movimento estudantil do curso de filosofia da Universidade de São Paulo (USP), baseando-nos nas experiências de luta de 2016 e problematizando as contradições envoltas na pauta por permanência estudantil, feitas ao longo do mesmo ano. Para tanto, convidaremos o leitor a adotar uma posição quanto ao problema da interrupção da vida acadêmica normal dos estudantes, em situações adversas (piquetes ou reformas imprevistas na estrutura física do patrimônio universitário). Por fim, partindo dos possíveis posicionamentos quanto ao cenário proposto, poderemos avaliar as predisposições políticas estudantis para lutar, seguindo ou não as regras e protocolos das estruturas oficiais de poder, internas à universidade.

Palavras-chave: movimento estudantil - pauta por permanência - métodos de luta - piquete.
\end{abstract}

"a significaşão histórica atual dos estudantes e da universidade, a forma de sua existência no presente merece (...) ser descrita apenas como parábola..."

Benjamin, Documentos de cultura, documentos de barbárie: escritos escolbidos, p. 151.

\section{Introdução}

À primeira vista, parece das maiores contradições que, nos protestos estudantis do ano de 2016, os mesmos defensores da pauta da permanência estudantil sejam os mesmos que deliberam por piquetes para bloquear o acesso e, portanto, a permanência dos estudantes em uma das partes mais importantes da estrutura física universitária, sem a qual ela é inconcebível: a sala de aula. Como podem se livrar da contradição lógica aqueles que, ao mesmo tempo, querem uma melhor permanência estudantil e barram a permanência estudantil com greves, piquetes e atos dos mais variados?

O presente texto pretende discutir maneiras de encarar essa contradição e debater o modo pelo qual questões políticas gerais estão ligadas a pautas específicas estudantis. Parte, para tanto, de fatos corriqueiros que qualquer estudante de filosofia (mas, não só de

\footnotetext{
${ }^{1}$ Mestrando em Filosofia pelo Departamento de Filosofia da Universidade de São Paulo - USP. E-mail: orlando.pimentel@usp.br.
} 
filosofia) já teve de pensar sobre, senão topar com. ${ }^{2}$ Permeará este texto também a preocupação em pensar a ocupação dos estudantes no espaço público e as interferências que podemos ou não realizar neste espaço. Em seu devido lugar, tais temas trarão oportunidade de relacionarmos o movimentar individual do estudante, em meio à estrutura universitária que nos cerca, com a noção de liberdade, enquanto escolha entre possibilidades contextualizadas. Por fim, sem a pretensão de dar os termos últimos do debate, almejamos propor formas de politizar as discussões sobre o movimento estudantil que, não raro, têm sido feitas sob a marca da estereotipação, das acusações criminais e da desqualificação indevida de indivíduos, deixando de lado toda carga política das ações estudantis cotidianas.

\section{O movimento estudantil exemplar}

Gostaria de refletir sobre o movimento estudantil, para não gerar muitas polêmicas logo de início, partindo de exemplos bem corriqueiros das movimentações feitas por estudantes transeuntes do Departamento de Filosofia da Universidade de São Paulo (USP). Começo, para tanto, com uma espécie de experimento mental sobre o cotidiano de um estudante imaginário, o prédio no qual frequenta suas aulas e sua vida universitária. ${ }^{3} \mathrm{O}$ experimento permitirá, partindo das conclusões do leitor acerca do cenário proposto, traçar algumas linhas de argumentação distintas para mais de um posicionamento sobre o movimento estudantil, seus métodos de intervenção no cotidiano e suas predisposições para o conflito institucional. Sigamos ao experimento:

Imaginemos que para entrar no Departamento de Filosofia da USP, nosso estudante imaginário, entra no prédio através de uma das seis ou cinco entradas oficiais possíveis do prédio do meio $^{4}$, que permanecem abertas usualmente das $7 \mathrm{~h}$ às $23 \mathrm{~h} 30 \mathrm{~min}$. Nosso estudante entra nas salas de aula, os professores também o fazem, constantemente seguindo uma grade horária vespertina ou noturna. Nosso estudante, ávido por beber o conhecimento da fonte, almeja o melhor dos lugares, quarta ou quinta fileira, numa distância que permita observar todo o discurso e idiossincrasias de cada um de seus

\footnotetext{
${ }^{2}$ Literalmente topar com o problema, no caso dos piquetes com "cadeiraço", ou seja, com a obstrução física dos corredores das salas de aula, utilizando cadeiras.

3 "Experimentos mentais" são geralmente utilizados em áreas como a filosofia da mente, para definir posições teóricas acerca de problemas de difícil observação fática. No nosso caso, estamos utilizando essa ferramenta conceitual com a única diferença de que o cenário a ser exposto, apesar de ser em grande medida caricatural em sua descrição, seria um cenário possível de ocorrer fatidicamente no cotidiano estudantil.

${ }^{4}$ A título de simplificação, desconsidero os estudantes que pulam as janelas do espaço verde e a porta deste espaço que abre só a partir de ofícios ou quando a vigilância vacila em sua atividade de proteção das nãoentradas oficiais.
} 
professores, o que lhe servirá de assunto predileto entre os colegas, no intervalo das aulas. Por isso, chega meia hora antes do início da aula, para não perder seu lugar de estima. Após a aula, estuda bastante na biblioteca (chega correndo para pegar as cabines de estudo e os livros recomendados nas aulas); come, no bandejão, nos seus lugares preferenciais do fundo, onde o barulho é menor e pode satisfazer-se com mais calma. Há filas grandes e claro que ele reclama, pois as filas são das mais ardilosas inimigas da liberdade e do direito de ir e vir, dos poucos direitos que pensa ainda poder dizer que é seu. Nosso estudante utiliza todo seu ânimo para se dedicar ao seu dia a dia institucional e é exemplar em seu desempenho, gerando a contrapartida social que a faculdade demanda, com bom rendimento, boa produtividade e almejando terminar sua graduação em quatro anos cravados.

Não só de flores segue a vida de nosso estudante, no entanto. Duas situações alteram a rotina de dedicação exclusiva de nosso colega: a primeira situação é a das alterações súbitas de horários de funcionamento do prédio e das reformas estruturais que geram barulho, fecham portas, constroem paredes, desviam corredores e dificultam seu fluxo normal de aulas. Apesar dos transtornos, segundo os posicionamentos oficiais da instituição, tais reformas são feitas a fim de trazer melhorias e um leque maior de possibilidades aos estudantes; a segunda situação é a das greves, dos piquetes e ocupações, organizadas por outros colegas de curso, mas que impedem por completo sua atividade acadêmica normal e são, em sua opinião, o meio mais violento, mais avesso ao diálogo e, por consequência, mais antiuniversitário que há, de tal forma que, em seu entendimento, seria justo indagar se os partícipes de tais atividades deveriam sequer ser chamados de estudantes $^{5}$. No entanto, assim como na situação das reformas, os organizadores de piquetes e greves dizem que o fazem para melhorar a vida estudantil e institucional.

Pergunta-se ao leitor, levando em consideração as duas situações (chamemos de S1, a das reformas, e S2, a dos piquetes, greves, etc.): na concepção de nosso estudante exemplar imaginário, em ambas as situações, sua liberdade e seu direito de ir e vir, dentro da instituição, são irremediavelmente feridos, sem que possa reconhecer qualquer

\footnotetext{
${ }^{5}$ Aqui entendemos o duplo sentido do termo pejorativo "estudante profissional": trata-se, em primeiro lugar, de um não-estudante, alcunhado pelos seus pares como tal e acusado de fazer das greves, piquetes e atividades políticas estudantis um meio de vida, inclusive, em mais inflamadas acusações, recebendo salários de partidos políticos de esquerda. Em segundo lugar e levando em conta as palavras de um filósofo que pensou sobre o movimento estudantil de sua época, podemos dizer que "Onde a ideia dominante da vida estudantil é a profissão e o emprego, não há lugar para a ciência" (BENJAMIN, Documentos de cultura, documentos de barbárie: escritos escolbidos, p. 155). Portanto, ser chamado de um "estudante profissional" é ter de si tanto negado o reconhecimento enquanto ser ciente que persegue, de boa fé, o conhecimento, quanto ter a sua formação reduzida à demanda mercadológica imediatista por mão de obra empregável, contrária à ânsia por autonomia que deveria ser característica da atividade crítica e filosófica.
} 
contrapartida de melhoria futura na condição estudantil? Se não, qual delas fere? Qual não fere?

\section{Possíveis posicionamentos}

São quatro as combinações possíveis de posicionamento acerca do cenário previamente exposto: S1 e S2 ferem a liberdade, S1 fere e S2 não, S2 fere e S1 não ou - a mais excêntrica, mas ainda assim possível - ambas não ferem. Começaremos por esta última que parece dos posicionamentos o menos provável.

Antes, no entanto, duas ressalvas precisam ser feitas. Em primeiro lugar, devemos lembrar que, apesar de estarmos partindo de um único estudante, em um cenário em grande medida caricatural, a situação deve ser levada em conta a sério ao pensarmos o movimento estudantil em todo seu teor político proposto neste texto. Reconhece-se aqui que mesmo que o estudante imaginário não queira fazer parte daquilo que, em sua concepção, seja tão somente o movimento estudantil dos "estudantes profissionais", ainda assim, numa acepção bem mais cotidiana e menos estereotipada de movimento estudantil, enquanto estudante da e na instituição, transeunte de seus corredores, portanto em movimento físico pela universidade pública, ele deve ser levado em conta como parte importante da diversidade dos movimentos de estudantes. A possibilidade mesma de propor uma perspectiva coletiva de movimento estudantil, para além da rotina individual, partindo de algo tão corriqueiro quanto o cotidiano dos transeuntes que se assumem enquanto estudantes de filosofia, tem como vantagem não entrar em questões ardentes sobre a representatividade legal ou não do movimento estudantil, suas entidades e legitimidade. Tomaremos os movimentos estudantis, individuais e coletivos, enquanto um fato que possui efeitos relevantes ao considerarmos a ampliação ou restrição de nosso leque de possibilidades institucionais. Do mesmo modo, quando mencionarmos as reuniões de Departamento, Congregações das Faculdades ou o Conselho Universitário, não teremos em conta a representatividade e a legalidade, mas, antes, os limites das articulações estudantis nestes espaços, ainda que seus movimentos dentro das instâncias deliberativas oficiais reduzam-se, na maior parte das vezes, a compartilhar da possibilidade de passar horas sentado, discutindo os rumos burocráticos, sem gerar grandes impactos ou transformações permanentes nas estruturas de deliberação universitária.

Uma segunda ressalva seria a de que, em prol de não enredarmos em contendas profundas sobre se há ou não algo como a liberdade individual, em sentido ontológico, deliberadamente adota-se aqui o termo "liberdade" significando tão somente a ação de optar entre possibilidades postas diante de nós, no nosso dia a dia. Para esta noção próxima do senso comum, os problemas da liberdade estudantil seriam tais como: entrar ou não na aula? Estudar ou ir para o bar? Reconhecer ou não uma assembleia estudantil? Dar ouvidos ou 
não a um pretenso defensor do futuro da universidade pública? Desviar ou seguir para a biblioteca? Propor ou não propor o piquete? Chamar ou não a polícia para o Movimento Estudantil? Aderir ou não à greve? Fazer greve de pijama ou organizar alguma atividade? Etc.

Feitas as ressalvas, passemos aos comentários quanto às posições possíveis em nosso cenário.

\section{$O$ indiferentemente livre}

Podemos dizer daquele que opta por negar a interferência de ambas as situações quanto à liberdade do nosso estudante exemplar, que ele vê o cenário partindo de uma perspectiva "indiferentemente livre". Não há amarras para este viés de liberdade. A posição acerca dos conflitos institucionais cotidianos e das possibilidades de movimento dentro da instituição, mesmo no sentido simples de deslocamento físico, pode ser caracterizada, neste caso, como uma adaptação constante e imediata a tudo que lhe é posto de contrário no cotidiano. A bem da verdade, não há nada de contrário ao cumprimento das opções cotidianas para o indivíduo pensado desta maneira, pois:

Ou [1] a liberdade encontra-se para além de qualquer determinação institucional e política e, portanto, desatrelada de todo constrangimento, mesmo físico, ao transladar individual pelo mundo, sendo a liberdade aqui uma entidade de realidade própria e isolada de qualquer contexto. ${ }^{6}$ Chamemos esta de uma posição totalmente indiferente e livre.

$\mathrm{Ou}[2]$ sua liberdade transcende os problemas institucionais e políticos particulares do ambiente universitário, mas acredita poder ser afetada pelos constrangimentos espaciais e temporais de outras instituições. Desta forma, não haveria problema, para nosso estudante, em retornar para a casa por conta de um piquete, pois não haveria qualquer sentimento de pertença ao curso ou qualquer elo com sua normalidade. Reconhecendo-se enquanto um estudante de filosofia (num sentido muito fraco do termo), sua indiferença se encontraria circunscrita ao contexto universitário. Chamemos esta de uma posição contextualmente indiferente e livre.

Ou [3] nosso leitor é contrário à restrição de sentido do termo "liberdade", com a qual nos comprometemos a trabalhar neste texto, e não acredita que reformas ou piquetes possam ferir algo como a "liberdade" por optar pelo que quer que seja, pois, em última análise, não haveria algo como a própria possibilidade de optar. A Liberdade seria uma ilusão necessária dentro de uma dinâmica imanente, da qual seríamos tanto parte quanto

\footnotetext{
${ }^{6} \mathrm{O}$ que também significaria uma completa falta de afetação quanto à cadeia de justificativas ou críticas feitas tanto pela instituição (na S1), quanto por movimentos coletivos de estudantes a reivindicar uma causa comum (na S2).
} 
modos de existência, o que exigiria uma reformulação e revisão completa do viés deste texto. Essa perspectiva, apesar de poder ser muito interessante, não nos traria benefícios para discutir a escala cotidiana do movimento estudantil aqui proposta. Enveredaríamos, inevitavelmente, em um outro contexto, tomado tão somente por esse tema.

A posição do estudante totalmente indiferente e livre é aquela sobre a qual valerá a pena tecer alguns comentários, já que é a posição na qual há um desejo manifesto de ser reconhecido enquanto estudante de filosofia, ainda que decididamente alheio a tudo e todos.

O cenário de total e indiferente liberdade do estudante é um cenário, se aceitarmos a limitação do termo "liberdade", impossível de se consolidar de fato, sem que o nosso interlocutor aja com má-fé na defesa de sua posição. A liberdade enquanto escolha cotidiana entre uma diversidade de posições e situações exige, lógica e fisicamente, que a liberdade individual se situe quanto a um complexo cotidiano de escolhas que se interseccionam às de outrem e interagem com a estrutura física da instituição, seus acessos e suas permanências possíveis. Ao ocupar um determinado espaço na instituição, seja com uma posição representativa (digamos, estudante responsável de um evento, Representante Discente, pesquisador da Iniciação Científica, etc.), seja numa posição espacial (dentro ou fora da sala de aula, na fila do bandejão, etc.) - portanto, nos dois sentidos que há quando dizemos que "temos uma posição" -, ser ou estar em uma posição implica não estar em outra e impedir a possibilidade que mais alguém compartilhe exatamente a mesma posição que a sua. Levando isso em conta, uma liberdade descontextualizada, individual e completamente sem afetação quanto ao complexo de desejos, movimentações alheias e barreiras (humanas, de concreto ou do que for) seria benéfica apenas para pensarmos sobre hipotéticos estudantes autômatos ou virtuais que se moveriam num espaço de ocupação abstrata da instituição. Seria talvez uma liberdade defensável partindo da perspectiva dos sistemas de informação universitária (o Júpiter, por exemplo), em que somos o próprio número USP, tratados como elementos do conjunto lógico e operacional dos alunos matriculados. Mas, felizmente, ainda não existem estudantes autômatos e os sistemas de informação, em termos fenomenológicos, não possuem, por si só, consciência, perspectiva ou opinião.

É, portanto, errônea a perspectiva individualizada e abstrata da liberdade estudantil, pois não considera o fato de que podemos sentir maior ou menor restrição de nossa liberdade, em situação, entre outros estudantes transeuntes e entre as estruturas universitárias pelas quais transitamos.

Desde já, podemos dizer que todo estudante é um ocupante do patrimônio público universitário (em sentido físico-estrutural e também enquanto alguém que permanece e é transeunte do e no patrimônio tradicional de produção do conhecimento que é a universidade). Ainda que queira se restringir ao mero papel de indivíduo com um número 
para ser identificado tão somente pela instituição e só por ela, sua presença não pode prescindir de seu caráter político, já que, enquanto estudante-ocupante, sua posição é a nãoposição de um outro, e, igualmente, não pode deixar de lado os rastros de seus hábitos e predisposições de movimento que o influenciam para além da vida institucional da universidade. O espaço da Faculdade de Filosofia e da Universidade, por sua vez, ao fazer parte do contexto maior da cidade, do Estado, do País e do Mundo, não pode também ser considerado enquanto entidade isolada e alheia ao que ocorre para além de seus limites físicos ou institucionais.

Segue-se que todo estudante é, inevitavelmente, um ocupante da instituição e é dessa maneira que devemos nos pôr ou nos indispor, entre nossa categoria estudantil, ao adotarmos uma posição seja quanto a um contexto S1 ou S2. Se existe o reconhecimento de que somos estudantes da universidade pública, o papel de mero observador, aquém do próprio cotidiano, não pode servir para os problemas colocados por este texto.

Deixar de lado o fato de que todos somos ocupantes do espaço público, quando do problema dos rumos da liberdade dos estudantes neste mesmo espaço, é fazer uma discussão que não se permitirá perguntar: que lugar eu assumo intencionalmente enquanto um estudante, ainda que transeunte, da instituição? Se há transformações estruturais na universidade, quais os critérios para definirmos aquilo que deve ser conservado ou alterado enquanto Patrimônio universitário? Quem define esses critérios? São eles incontestáveis? Esse Patrimônio é, de fato, Público em que sentido? Não são as estruturas físicas públicas, também, transeuntes da Pólis, nas quais podemos ou não interferir?

\section{O confiante na Instituição}

Daquele que opta por negar a interferência institucional de S1 quanto à liberdade do nosso estudante exemplar, mas que vê S2 como a principal responsável pelos seus grilhões, podemos dizer que ele vê o cenário sob uma perspectiva do "confiante na Instituição".

As decisões da Congregação, do Conselho Universitário, a escolha final do Reitor pelo governador do Estado de São Paulo, reformas, alterações das mais inoportunas, intervenções policiais no campus, fechamento de espaços sindicais, estudantis ou creches, etc., tudo isso é feito, segundo esta posição, rumando para a ampliação das possibilidades institucionais e, por consequência, da liberdade dos indivíduos na instituição, sejam eles estudantes, funcionários ou professores. Basta que as deliberações sejam institucionais para que estejam, de pronto, legitimadas.

Não haveria motivos para quaisquer outras instâncias organizativas para além daquelas previstas no estatuto universitário, que seriam as responsáveis pelo funcionamento normal e o progresso da instituição. Os conflitos entre categorias e demandas diversas 
deveriam, em prol da harmonia e progressiva transformação institucional, ser digeridos dentro do metabolismo político da própria instituição, atravessando seus diversos conselhos. Uma assembleia estudantil, neste caso, é uma perda de tempo e de energia que poderia ser gasta assumindo e disputando papéis de representação discente, talvez o máximo de envolvimento concebível.

Esta posição, diferente daquela sobre a qual primeiro tecemos alguns comentários, tem como vantagem reconhecer que, sim, há conflito. Este conflito, no entanto, ao transpor as estruturas tradicionais previstas pelo aparato Jurídico universitário (ou seja, suas congregações e conselhos), poderia pôr em perigo todo o funcionamento da instituição e trazer não só desordem, como episódios tão arbitrários quanto o dos piquetes e greves, que, no fim das contas, privilegiariam apenas interesses privados de pequenos grupelhos sindicais e de estudantes profissionais.

Ora, a essa posição devemos antepor sua própria preocupação quanto ao perigo de dominação do interesse privado de pequenos grupos políticos sobre o bom funcionamento da instituição pública e, sem nem botar em questão a rigidez e pouca democracia interna das instâncias deliberativas oficiais, perguntar: assumindo essa estrutura tal como ela é, qual tem sido a interferência do conflito institucionalizado oficial quanto ao combate aos interesses cada vez mais presentes de grupelhos privatistas dentro da universidade pública? Tem sido tal atuação eficaz para nossa faculdade de ciências humanas quando comparada a outras faculdades? Esses grupos privatistas também não agem dentro do metabolismo político da instituição e trazem contradições para o caráter público das reformas, alterações do dia a dia universitário? Essa influência privada não afetaria também o como estudamos filosofia?

Nós devemos ter em vista estes pontos, para que, ao julgarmos a coerência das acusações feitas contra movimentações estudantis, no mínimo, exijamos daqueles que encampam a luta institucional com o maior dos otimismos, que demonstrem o mesmo entusiasmo para denunciar o papel nefasto de empresas e fundações privadas se imiscuindo nos rumos da universidade; que tenham o mesmo ânimo para levar a ferro e fogo toda crítica aos grupos minoritários e que abram as portas de seus conselhos (em si compostos por uma minoria da comunidade universitária), permitindo muito mais participantes com voz e voto em suas deliberações e que, coerentes com o que pensam, não reconheçam o processo universitário de votação para reitor e, muito menos, o governador do Estado de São Paulo, por encampar e perpetuar uma estrutura tão prol grupelhos quanto a da Universidade de São Paulo. 


\section{O entusiasmado dos piquetes}

Optar por afirmar a interferência institucional de S1, mas negar a de S2, quanto à liberdade estudantil, é o modo de ver daquele que chamamos de o "entusiasmado dos piquetes".

Essa perspectiva não é necessariamente só dos pretensos estudantes profissionais estereotipados, mas de todo e qualquer estudante que reconheça apenas nos piquetes e greves universitárias a salvação para a instituição de ensino superior pública. Seu engajamento e espírito de sacrifício fazem com que privilegie sempre o coletivo (universitário), ainda que este coletivo não se mostre tão recíproco em seu reconhecimento para com as lutas estudantis. Em prol de organizar um piquete (com "cadeiraço", tanto melhor), agiliza e apressa as assembleias de curso, se importando pouco com o trabalho de base. Quando da agonia de não poder contar com outros espíritos aguerridos e compromissados com a luta cotidiana, não vê problemas em ter de centralizar a maior parte das tarefas organizativas nas reuniões do Centro Acadêmico e, por fim, passa a ter sua imagem associada à do defensor dos piquetes a todo custo. Não compreende que tanto um piquete feito em momento inoportuno e quanto o centralismo agem na contramão de seu ideal universitário.

Não é de se espantar que este ânimo entusiasmado tenda a recair rapidamente, após um ou dois anos de militância árdua nas entidades da faculdade. Pelo menos dois motivos podem aqui ser expostos como possíveis causas para tal esmorecimento:

Primeiro: ao centralizar sempre a responsabilidade pelas atividades coletivas estudantis e, com ansiedade, procurar impor a todo custo na cabeça de outros colegas de curso a necessidade de sair da sala de aula para aderir às lutas, não vê problemas em terceirizar o bom e velho trabalho de base, na base de um piquete oco, apressado e sem ativismo cotidiano que the dê algum lastro de legitimidade. Opta, portanto, semelhantemente ao otimista crente na eficácia institucional, pela urgência do intervir, centralizadamente, e esquece-se que movimentos coletivos exigem um preparo constante de formação e presença cotidiana na vida dos estudantes. Greve e piquete são instrumentos tradicionais da luta social e não o fim último dela. Passagem em sala, o compromisso de manter acessível o Centro Acadêmico e espaços estudantis, estimular tarefas bem divididas e diversas entre os estudantes, são a verdadeira antessala do apoio às lutas estudantis, independente dos métodos que os estudantes venham, coletivamente, a se propor.

Segundo: nosso ativista entusiasmado tem um problema, em grande medida mereológico, de que não consegue dar conta. Ao confundir o ânimo das lutas universitárias com o ânimo para com o todo do conflito social, esquece-se de que, enquanto instituição pública que é, a universidade encontra-se enquadrada ao complexo político-econômico brasileiro e mundial. A austeridade que reina sobre o cotidiano brasileiro, ainda mais em 
tempos de crise e golpe de Estado, lança sobre o cotidiano universitário suas dificuldades quanto à credibilidade e permanência da universidade pública, enquanto pública, nos episódios de toda e qualquer deliberação institucional. A desconfiança, portanto, ramificase para todo e qualquer conflito cotidiano que possamos empreender entre nossos pares. A luta universitária, assim como toda luta considerada enquanto aquela de uma esfera mais local, possui seus bastidores não locais que podem ser até mais determinantes que as estruturas da organicidade institucional, validadas por leis internas. Todas as lutas específicas e movimentações, portanto, possuem uma franja de relações que podem transformá-las em lutas e movimentações gerais, que questionam a liberdade, o acesso e a permanência estudantil as relacionando aos limites estruturais do Estado. Levando em conta, portanto, que os limites da instituição não são assim tão logicamente determinados, em nossa opinião, é dever de um ativismo estudantil consequente propor aos seus pares os itinerários que trariam o geral ao específico e vice-versa.

Assim sendo, ao acreditar que o todo se comunica de imediato com a parte, esta posição deixa de reconhecer a importância do engajamento universitário em lutas para além dos muros da universidade, que poderiam alterar a conjuntura política geral que nos afeta $\mathrm{O}$ cotidiano. Neste sentido, aquele que aposta todas suas forças na pressa do resultado de interrupção via lutas específicas, deixa de lado a possibilidade de aprender como ocupar politicamente o espaço público (e até mesmo o privado) com outros movimentos sociais, utilizando-se das ferramentas mais diversas para luta.

\section{Os que se topam}

Por fim, àqueles que reconhecem que ambas as situações interferem na liberdade e direito de ir e vir de nosso transeunte, chamaremos de adeptos da perspectiva dos "que se topam".

Nesta perspectiva assumimos que os estudantes se topam com as estruturas, com as filas, com as reformas, com os piquetes, com professores, com funcionários, com outros estudantes, com portas fechadas dos conselhos, com portas fechadas de centros acadêmicos, com a burocracia universitária, etc.. Encontram-se predominantemente perdidos e incertos quanto ao rumo pelo qual as decisões dentro da universidade são tomadas. A falta de referências organizativas democráticas acessíveis dentro da instituição igualmente contribui para que estejam incertos também quanto a seu potencial papel político e capacidade de intervenção concreta no dia a dia. Sabem, no entanto, que muitos espaços não lhe são permitidos em termos legais e a mera tentativa de transpor tais barreiras e bloqueios institucionais seriam um convite para sofrerem as represálias do Estado. 
Esta posição é aquela com a qual me identifico pessoalmente e com a qual julgo podermos melhor conduzir o debate, sem o otimismo institucional engessado ou o entusiasmo piqueteiro a todo custo, ambos em grande medida despolitizadores e descontextualizadores. A presente postura, no entanto, não é, de modo algum, semelhante àquela do que, em dúvida quanto aos rumos da política e dos movimentos políticos, recolhe-se ao mero papel de observador passivo das alterações institucionais que têm sido marcadas pelo desmonte público, em diversos níveis (estadual, federal, etc.). Sentimos que somos parte do desmonte. Se nos topamos e nos conflitamos é porque temos por certo que grandes pressões fazem nosso cotidiano estudantil mais ou menos obstruído quanto a nossas possibilidades, o que, necessariamente, contribui para gerar nossas convulsões internas.

Ainda consoante a perspectiva dos que se topam, o direito de ir e vir é, antes de tudo, um direito coletivo de irmos e virmos, de acessos e permanências complexas, que não é decidido tão somente no instante em que topamos com um desvio da normalidade cotidiana, como num cadeiraço ou num prédio fechado ao bel prazer das decisões institucionais. Chamar tal direito de "seu" e ter em mente o uso do pronome possessivo como indicativo de posse privada de tal direito é, segundo nossa posição, uma abstração tão sem fundamento quanto aquela dos que julgam possuir uma liberdade indiferente a qualquer conflito e isolada das estruturas públicas e de outros seres livres.

Quanto aos piquetes ou reformas, eles podem ser vistos com um viés menos estereotipado. Se eles interferem em nossas possibilidades cotidianas, não é de um modo derradeiro. Não são apenas interrupções abruptas da vida acadêmica, sempre sem qualquer ganho. Principalmente com relação aos piquetes, acreditamos que possam, também, permitir melhores possibilidades futuras, apesar de um breve período de constrangimento de possibilidades cotidianas. Como outros movimentos sociais já demonstraram ao longo da história, o uso deste instrumento de luta política, para pressionar instituições rumo à conquista de novos direitos, foi efetivo e trouxe conquistas com as quais até hoje somos beneficiados. Portanto, quando alinhados a uma perspectiva de democratização dos fóruns internos, ampliação dos acessos e do atendimento às necessidades acadêmicas e materiais básicas dos estudantes ${ }^{7}$, tais métodos devem ser sim utilizados.

\footnotetext{
7 Não só necessidades imediatas como alimento, residência, mas também necessidades específicas de um curso como o de filosofia (cursos de línguas, de introdução à escrita de trabalhos acadêmicos e métodos de pesquisa).
} 


\section{Conclusão}

Não parece que o movimento estudantil, pensado através do auxílio desse cenário imaginário, em qualquer uma das posições acima analisadas, consiga se livrar da contradição lógica de defender uma melhor condição da liberdade e potencialidade dos estudantes, através de pautas como a da permanência estudantil, e, ao mesmo tempo, propor uma obstrução física à permanência estudantil na sala de aula (ou seja, não defender a permanência estudantil na sala). A razão pela qual tal contradição permanece e permanecerá, no entanto, parece-nos um pouco óbvia: a política não obedece às leis do cálculo de proposições.

A lógica de predicados não é suficiente para dar conta da complexa rede de sentidos das deliberações nos e dos espaços organizativos da universidade, sejam elas provenientes do metabolismo institucional ou de assembleias estudantis; não é igualmente capaz de mapear e computar todas as redes de influência que solapam o caráter público da instituição e de suas estruturas deliberativas oficiais ou não.

Querer, com a lógica, abstrair a política de seu aspecto situacional e espacial, literalmente tirando o corpo fora dos problemas que interferem em nosso cotidiano, não parece ser algo tão simples ou mesmo possível de ser feito, sem que uma grande descontextualização ocorra. Observamos que os termos empregados na situação 2 "piquete" e "greve" - são, tal como o termo "política", "democracia" e "ocupação", eminentemente marcados por sentidos espaciais e posicionais, tanto quando assumimos uma posição, uma opinião, quanto quando significam que permanecemos em algum lugar.

O termo Política, como já é bem sabido, dizia respeito a tudo que ocorre na Pólis. O termo francês "Grève", no início do séc. XIX, significava terreno de cascalho e areia. A "Place de Grève" na França, era assim chamada pois se situava nas margens do Rio Sena, cujo terreno arenoso e de cascalho servia de palco da reunião de desempregados e descontentes com as condições trabalhistas. Por uma relação toponímica o que era o nome de um lugar passa a designar também a ação daqueles que costumavam se reunir naquela praça. $^{8}$ No Brasil, os operários e estudantes utilizavam a palavra "parede" para indicar o processo de abstenção ao trabalho ou sala de aula. Daí o termo furar greve, pois antes de tomarmos de empréstimo do francês o termo greve, os estudantes diziam que "furaparedes" eram aqueles que não participavam da greve decidida nas assembleias. ${ }^{9}$ O "Demos" de "democracia" pode ser traduzido não apenas como povo, mas também como bairro, distrito ou local das comunidades atenienses.

${ }^{8}$ Cf. CASTRO, Greve: fatos e significados, p. 12.

${ }^{9}$ Cf. VASCONCELOS, Lições de filologia portuguesa, p. 352. 
Ora, se os termos políticos que povoam nossa discussão não raro tem esse duplo sentido - espacial e posicional -, algo mais do que coincidência pode ser atestado aqui, ao menos pensando de modo indutivo. Nossa hipótese é a de que o conflito entre posicionamentos políticos sempre envolve uma relação entre estar ou não-estar - que não cabe à lógica formal dar fim -, entre espaços de maior ou menor restrição de liberdades e que devem ser contextualizados quanto às diversas câmaras e labirintos de poder aos quais se encontram vinculados.

Aos debates futuros quanto às formas de luta e métodos com os quais o movimento estudantil se expressa, esperamos que este texto possa ter ponderado diversas posições estudantis que, apesar de caricaturais, ressoam nos corredores do Departamento de Filosofia. Não houve aqui pretensão filosófica e a mobilização de bibliografia da área foi intencionalmente evitada, em prol de uma discussão mais despreocupada, entre estudantes. É inevitável, a nosso ver, no entanto, que interrupções da normalidade institucional ocorram, pois, enquanto fenômenos sociais, formas embrionárias de greve encontram-se presentes nas sociedades desde antes do nascimento da Filosofia ${ }^{10}$. Foram e continuaram a ser métodos que já demonstraram sua força de intervenção na mudança das estruturas desiguais de poder do todo social. Enquanto estudantes e ocupantes de parte do todo social que é a universidade pública, devemos nos valer das mais politizadoras experiências de greve, piquete e, mesmo, do famigerado cadeiraço, a fim de que sejam construídas boas paredes estudantis.

\title{
BETWEEN INSTITUTIONAL AND STUDENTS' BARRIERS: THE STUDENTS' MOVEMENT, ITS POSITIONS AND STRUGGLES
}

\begin{abstract}
The objective of this paper is to reflect about the movement of the students of Philosophy from the University of Sao Paulo (USP), based on the struggles of 2016, which showed contradictions concerning their tactics and goals. In order to do so, we invite the reader to assume a position regarding the interruption of the academic normal life of the students in adverse situations (strike pickets or unexpected structural reforms in the university architectonic heritage). At last, from the possible positions regarding the proposed scenario, I evaluate the political predispositions of the students in struggle, whether following or not the rules and official protocols of power within the university.
\end{abstract}

\footnotetext{
10 Estima-se que a primeira atividade de abstenção de serviço date de 2100 a.C., em Tebas. Cf. CASTRO, Greve: fatos e significados, p. 10.
} 
Keywords: students' movement - auxiliary structures demands - methods of struggle - strike pickets.

\section{Referências Bibliográficas}

BENJAMIN, Walter. Documentos de cultura, documentos de barbárie: escritos escolbidos. Tradução: Celeste H. M. Ribeiro de Sousa. São Paulo: Cultrix: Editora da Universidade de São Paulo, 1986.

BOBBIO, Norberto; MATTTEUCCI, Nicola e PASQUINO, Gianfranco. Dicionário de politica. São Paulo: Editora UNB - Imprensa Oficial, 2004.

CASTRO, Pedro. Greve: fatos e significados. São Paulo: Editora Ática - série princípios, 1986.

MIGLIOLI, Jorge. Como são feitas as greves no Brasil? Vol. 13. São Paulo: Editora Civilização Brasileira, 1963.

NEGRO, Antonio Luigi; GOMES, Flávio dos Santos. "As greves antes da "grève": as paralisações do trabalho feitas por escravos no século XIX". Ciência e Cultura. São Paulo, v. 65, n. 2, junho de 2013. Disponível em $<$ http://cienciaecultura.bvs.br/scielo.php?script=sci_arttext\&pid=S000967252013000200023\&lng=en\&nrm=iso>. Acesso em 05 mar. 2017.

VASCONCELOS, José Leite de. Lições de filologia portuguesa. Rio de Janeiro: Livros de Portugal, 1966. 